Printed in Great Britain

\title{
Form and Internal Structure of Cellular Aggregations in Early Escherichia coli Microcultures
}

\author{
By H. HOFFMAN AND M. E. FRANK \\ Department of Microbiology and Murry and Leonie Guggenheim Foundation Institute \\ for Dental Research, New York University, College of Dentistry, \\ New York 10, N.Y., U.S.A.
}

(Received 18 November 1960)

\section{SUMMARY}

A critical examination of results obtained with several microculture techniques showed that considerable variations may occur in the formation of cell aggregations, localized in definite zones in the preparation. The cellular aggregation studied in the greatest detail was the clonal microcolony. Time-lapse photomicrography of developing Escherichia coli microcolonies revealed that the arrangement of organisms follows an orderly pattern in both the smooth and rough phases. The genealogical history of the microcolony showed that cells are grouped by genealogical origin. The microcolonial configuration in both smooth and rough phases, at room temperature and $37^{\circ}$, consisted of closely packed arrays of organisms. At these temperatures, palisading appeared to be the primary movement through which the structure of the microcolonies was established. The usual palisading movement was of the sliding type, although buckling palisades were occasionally found in rough-phase cultures. At $44^{\circ}$, the microcolonial configuration in both smooth and rough phases did not invariably evolve through palisading. In these aberrant cases, the organisms appeared simply to push each other about, so that the final appearance was that of a loosely packed collection of organisms presenting as an irregular reticulum. Nevertheless, genealogical distribution remained orderly.

\section{INTRODUCTION}

The degree of order in a surface colony of bacteria must be great to allow for its regular form. A number of investigators have studied this phenomenon (reviewed by Knaysi, 1951), and they have suggested several hypotheses about the mechanisms involved. Nevertheless, as pointed out in Topley $\&$ Wilson's Principles (1955), we still know little of the internal structure of bacterial colonies. Two methods have been mainly used for studying this problem, impression preparations and direct microscopy of growing bacteria. There are, however, serious limitations in both these modes of investigation. Impression preparations do not allow tracing the development of a given microcolony from its inception in a single bacterium. The only record obtained from a constantly changing system is the stage at which cultivation is terminated. The series of developmental changes which occur, therefore, must be inferred from impression preparations of different microcolonies made at different time intervals. Another serious difficulty in this method arises from the fact that the preparations are fixed, rather than in the living state, when studied. Bouin's 
fluid, the fixative used by Bisset (1938) in a study of impression preparations of bacterial colonies, has been found to cause considerable shrinkage of bacteria (Minck, Ebel \& Minck, 1950). Thus the close approximation of bacteria which may be present in the living microculture would not be seen in fixed preparations. In the case of direct observation, the number of events under observation may be so large that it is impossible to become aware of some of them before the field has changed. It is for this reason that cell descent, for example, cannot be traced beyond the first few divisions.

The limitations of both these methods can be circumvented by time-lapse photomicrography of microcultures developing from an isolated organism. Although time-lapse photomicrography has been used for the study of the growth rates of individual cells (Bayne-Jones \& Adolph, 1932), and for the study of the effect of antibiotics on growing cultures of Escherichia coli (Pulvertaft, 1952), it apparently has not been applied for a detailed analysis of microcolony formation. We, therefore, have re-examined this problem with time-lapse photomicrography of smooth and rough phase Escherichia coli in coverslip cultures. A genealogical notation was devised to aid in the frame-by-frame analysis of the developing microcolony. The observations obtained have illuminated a number of conflicting reports, and have also revealed some new aspects of the order present in clonal microcolonies. In the course of the study, it was also found that the clonal microcolony was only one of a number of aggregations which characteristically developed in microcultures. These other formations are briefly described.

\section{METHODS}

Establishing the microculture. The strain of Escherichia coli employed (ATCC no. 8677) was studied in both the smooth and rough phases. The rough phase was obtained by holding a smooth culture in brain heart infusion broth at $37^{\circ}$ for 6 days. Isolation was from nutrient agar plates since the rough phase on beef brain heart agar was difficult to distinguish from smooth. The rough phase was verified by macrocolonial appearance on nutrient agar plates, the character of growth in nutrient broth, and by agglutination in salt solutions (Schneweis, 1959).

Both phases were grown in beef brain heart infusion broth for about $18 \mathrm{hr}$., and a heavily inoculated subculture was prepared and incubated for $1 \mathrm{hr}$. at $37^{\circ}$. Fifteen drops of the subculture were added with a capillary pipette to $5 \mathrm{ml}$. of diluted beef brain heart broth (4 parts water to 1 part medium). The diluted broth culture was then mixed with the pipette, which was used for inoculating the microcultures. A small number of cultivations were also made directly from both smoothand rough-phase broth cultures which had been allowed to age for a week or more.

The principal microculture method used consisted of surface inoculation of a small thin film of agar on a coverslip. A no. 1 coverslip $(22 \times 30 \mathrm{~mm}$. $)$ was immersed in $95 \%(\mathrm{v} / \mathrm{v})$ ethanol in water, drained by blotting one edge on a paper towel, and sterilized by flame. With the coverslip held at approximately 45 degrees to the horizontal, a drop of hot melted $2 \%$ water agar was allowed to run down the surface, leaving a thin streak of agar in the centre. After drying for 1 min., a drop of inoculum was placed on the agar streak and immediately drained off. The coverslip was left vertically in a Columbia jar (A. H. Thomas Co., Philadelphia, U.S.A.) for 2-5 min. It was then removed, and both ends of the agar streak were scraped off with a razor 
blade to leave an area of about $3 \mathrm{~mm} .^{2}$ in the centre. The agar film now had two cut edges and two edges formed from the free flow of agar (Fig. 1).

Two techniques were used for mounting the coverslip culture upon a glass slide. The method used for most of our observations is referred to as the 'open chamber' technique. In this method, the inoculated side was turned down, and the coverslip was then placed on two supports of no. 1 coverslips, approximately $1 \mathrm{~cm}$. apart, which had been placed upon a $25 \times 75 \mathrm{~mm}$. glass slide. The four edges of the inoculated coverslip were sealed with melted paraffin to prevent drying. It was verified by direct observation that the inoculated surface of the agar film did not touch the glass slide after the coverslip had been mounted upon its supports.

The second method for mounting the culture, which we refer to as the 'closed chamber' method, consisted of dropping the inverted coverslip culture directly upon the glass slide and sealing the edges with paraffin (Fig. 2). This is essentially the method used in most previous studies.

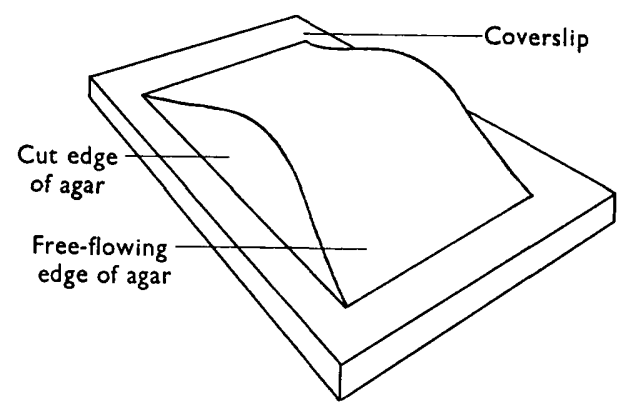

Fig. 1. Unmounted coverslip preparation for the open chamber method of cultivation.

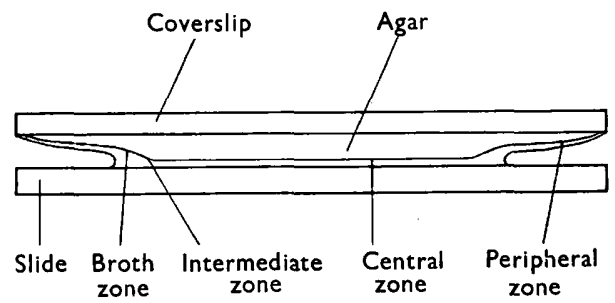

Fig. 2. Mounted coverslip preparation for the closed chamber method of cultivation.

Another method of microculture preparation tried was that of Fleming, Voureka, Kramer \& Hughes (1950); this was used in only a few cultivations. Bacterial broth culture was smeared out on a coverslip, and immediately after the smear had dried, it was flooded with melted nutrient agar at $50^{\circ}$. The preparation was then mounted upon a glass slide. We refer to this procedure as the 'Fleming closed chamber' technique.

The completed preparations were mounted within a Zeiss microscope stage incubator. Incubation was carried out at room temperature (about $25^{\circ}$ ), $37^{\circ}$ and $44^{\circ}$.

Photomicrograph methods. An isolated bacterium was located and observed with dark-phase contrast optics. In taking the photomicrographs, conventional light optics was used for the open chamber technique, and phase optics for the closed 
chamber methods. The photographs were taken at $3 \mathrm{~min}$. intervals with a Zeiss Contax camera, using a 100/1-30 oil-immersion objective lens. The condenser was not oiled. Kodak $35 \mathrm{~mm}$. High Contrast Copy film (Micro-file) was chosen for its high contrast, high resolution and small grain size. The illumination, generally, was with Zeiss electronic flash, but a tungsten lamp was occasionally used. The best optical conditions for photography for both smooth- and rough-phase cultures were obtained with the closed culture methods, and particularly with the Fleming technique.

The photographic record was initiated as soon as possible after the bacterium was located, but the length of observation for the time-lapse sequence varied. In some runs it was greater than $4 \mathrm{hr}$., at which time members of the 7 th generation were beginning to appear. In some cases incubation was carried out overnight, without time-lapse recording, to determine the effects of prolonged cultivation.

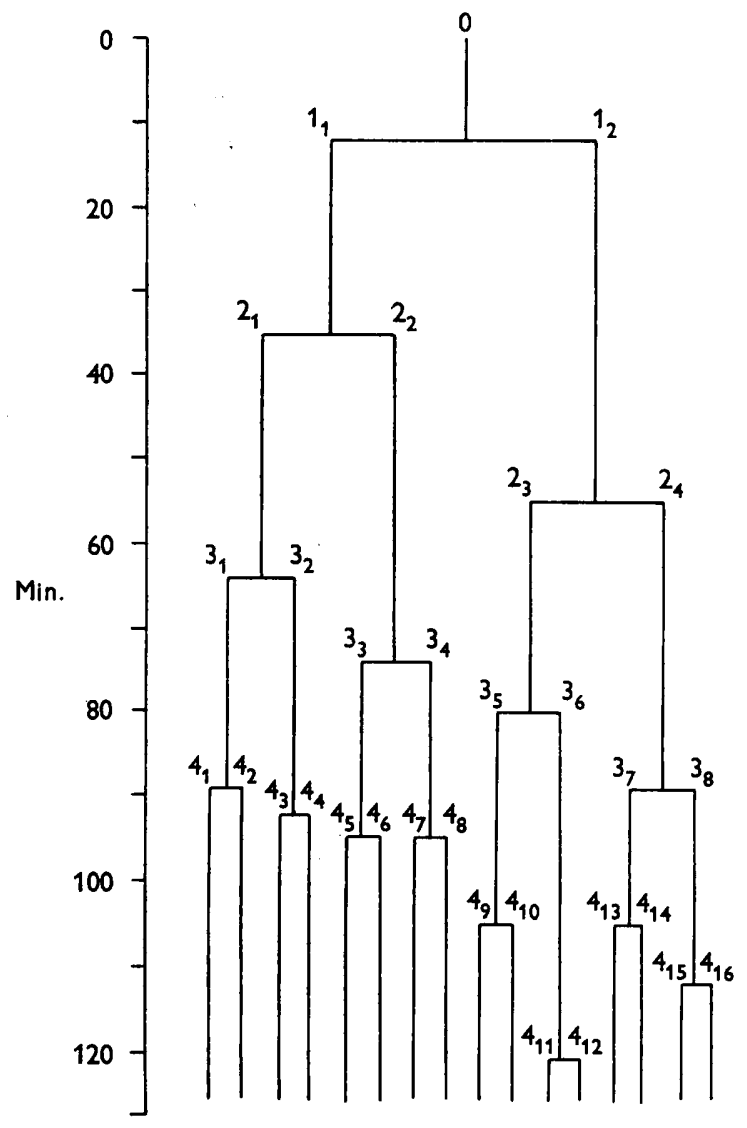

Fig. 3. Genealogical history of the clonal microcolony in Pl. 2, figs. 11-17.

Genealogy. Genealogical charts were drawn up to show descent in relation to time (Fig. 3). The original organism of the microcolony was designated as the 0th generation, and each succeeding generation was named in numerical order. The bacteria within a generation were given numerical subscripts. To distinguish between the two members of a pair arising from a division, that bacterium in the pair which 
went on to divide first was numbered first. Thus, of the two bacteria of the single pair of the 1st generation, the first bacterium to divide was numbered $\mathbf{l}_{1}$, while the other member of the pair became $\mathbf{1}_{2}$. However, when the two sisters of a pair divided at the same time, the first member was chosen as that bacterium which gave rise to the first daughter to divide. In the case of the bacteria present at the end of the time-lapse sequence, the division pattern of course could not be known, and therefore differentiation between the members of a sister pair was not possible. These last bacterial pairs were named with subscript numerals nevertheless. Designations of organisms were entered directly upon the photographic print in the analysis of runs (Pl. 2, figs. 11-14).

\section{RESULTS}

Examination of the microculture preparations immediately after inoculation showed that the seeding consisted of well isolated single bacteria and occasional groups of 2 or even 3 which lay clumped in a parallel array (palisade). Following incubation, regardless of the method of cultivation, large variations in the developed cellular aggregates of both smooth and rough phases were found. These variations were limited to definite zones which were parallel to the two edges of freely flowing agar, and extended the full length of the agar from cut edge to cut edge (Fig. 2).

\section{Peripheral zone}

At the freely formed borders of the agar film in both the open and closed chamber methods, small cellular aggregations appeared early in cultivation. At $37^{\circ}$, the bacteria in this zone were highly motile in the initial stages of incubation, so that any aggregations of bacteria, with the exception of rough phase chains, were soon disrupted. At room temperature, these bacteria were only slightly motile. Smoothphase daughter pairs tended to separate easily, while rough-phase organisms were found in motile chains of 4-8 members. The tenacity with which rough-phase bacteria remained attached to each other is illustrated in $\mathrm{Pl}$. 1, fig. 1, which shows one member of an 8-membered chain blurred from motion, while the remaining bacteria are sharply in focus and exhibit no motility. These rough-phase bacterial chains characteristically developed angular folds (Pl. 1, fig. 2).

Within 2-8 hr. after inoculation, motility appeared to decline, on both smooth and rough cultures, and bacterial aggregates reappeared. With rough-phase organisms, slowing down occurred early in cultivation $(2-4 \mathrm{hr}$.). The aggregates which then formed consisted of rods with considerable spacing between them, and with little or no order (Pl. 1, fig. 3). Overnight cultures showed bacteria of short lengths, comparable to those in the smooth-phase preparations, but the early disorder was still present. Although smooth-phase aggregates formed late in cultivation, the arrangement consisted of coccobacilli in a regular lattice (Pl. 1, fig. 4) which was maintained with continued cultivation. Both rough- and smooth-phase bacteria showed clearly discernible bridges of amorphous material between them, particularly in early stages of cultivation (Pl. 2, fig. 28). 


\section{Broth zone}

In the closed chamber method only, a zone developed, with both bacterial phases, just medial to the periphery in which the bacteria were freely suspended and grew in a diffuse pattern similar to that seen in hanging-drop preparations from broth. We refer to this as the 'broth zone' (Fig. 2).

\section{Intermediate zone}

This area was a transitional zone, usually quite narrow, which lay between the broth and central zones. Smooth-phase bacteria in this area usually formed short chains (Pl. 1, fig. 5); rough-phase bacteria formed somewhat longer chains. A single case was observed, with a rough-phase culture, in which the intermediate zone was much wider than usual, and the chains of bacteria were considerably longer than those normally found (Pl. 1, fig. 6). At the inner edge of the intermediate zone were 'transitional' microcolonies (Pl. 1, fig. 5). From the side of the transitional microcolony which bordered on the intermediate zone, motile bacteria sometimes broke away and migrated into the intermediate zone. Non-motile bacteria remained in the colony, but they tended to separate widely from each other. The opposite side of these colonies, toward the centre of the preparation, resembled the structure of the typical central zone microcolony.

\section{Central zone}

The 'central zone' is the innermost area of the closed chamber microculture, and its typical aggregation of organisms is the clonal microcolony, a formation found in all the types of preparations studied. With smooth-phase microcultures, the clonal microcolony at $37^{\circ}$ or room temperature consisted of closely packed arrays of bacteria whose general configuration appeared to depend upon the age of the original inoculum. When the inoculum consisted of $1 \mathrm{hr}$. culture which had been seeded from $18 \mathrm{hr}$. culture, the microcolony was quite regular and of a form which we refer to as 'compact'. From the time-lapse sequences (Pl. 2, figs. 11-17), it was apparent that post-fission palisading had an important role in establishing the compact configuration of the microcolony.

Typically, the first division of the original bacterium of the colony (0th generation) gave rise to a 2- or 3-membered chain (1st or 2nd generation). Continued growth along the long axis of the chain finally led to horizontal displacement of the proximal ends of a bacterial pair, and the bacteria then began to grow past each other (Pl. 2, figs. 11, 12). Several cases were seen, with the Fleming closed chamber technique, in which displacement of the end of a bacterium in the 2-member colony was vertical rather than horizontal. Palisading occurred in this case also. Further development of the compact microcolony was a consequence of cell growth, division and palisading. New palisades appeared only at the periphery of the microcolony.

When the microculture inoculum was obtained directly from a broth culture which had been held several days in the refrigerator, the microcolony configuration differed markedly from the compact forms obtained with an inoculum of vigorous young organisms. We now found microcolonial forms which we refer to as 'longitudinal'. In these cases bacteria of normal length (Pl. 2, fig. 24) or filaments exhibited reduced palisading, with the result that the bacteria accumulated as an 
elongated configuration. The early development of filaments at a lateral edge of a colony, in particular, most profoundly affected the colonial configuration, since the possibility for early palisading at that edge was eliminated.

In some cases, the longitudinal microcolony soon began to develop an accumulation of bacteria at one or both ends, and this form was then referred to as 'longitudinal nodal'. In all cases, unless a persistent filament was present, all microcolonies which deviated from the compact form eventually filled out the irregular indentations in their outline. They then closely approximated the general outline of the compact form. Thus, following overnight incubation, it was found that the general outline of smooth-phase microcolonies was round, regardless of what the early configuration had been. Differences in diameter and degree of piling up of bacteria of the microcolonies in a single preparation were observed in all the methods of cultivation used.

Overnight cultivation at $37^{\circ}$ or room temperature normally resulted in the formation of coccobacilli (Pl. 1, fig. 9), a finding similar to that observed in the peripheral zone of the microculture. Although our observations on this point were not thorough, it appeared that coccobacilli began to arise at about the 10th generation.

There was occasionally noted with rough-phase culture, in the closed chamber method, a persistent filament (Pl. 1, fig. 10) at the periphery of a microcolony, similar to the elongated $L$ form variant described by Hughes (1953) in anaerobic microcultures of Escherichia coli. In general, single bacteria in the rough phase appeared to be morphologically indistinguishable from single bacteria in the smooth phase.

No evidence was found for segregation of bacteria by age. Only one case was noted, out of several dozen microcolonies recorded, in which one of the two bacteria from the first division failed to grow. With this single exception, all bacteria which appeared in the course of all observed microcolonies grew continuously, and in most cases divided when the original length of the organism had approximately doubled.

With dark phase contrast optics, a distinctive difference was observed between the peripheral and interior bacteria of a microcolony. The peripheral bacteria appeared black while the interior bacteria were much more transparent, showing internal granules, and almost suggesting a partial lysis (Pl. 1, fig. 7). These differences were not affected by the most careful focusing down through the depth of the clone. The bleached-out appearance of the interior bacteria, in fact, was found as soon as the organisms began to palisade, and always appeared to be associated with bridging (Pl. 2, fig. 29).

In rough-phase cultures at $37^{\circ}$ and room temperature, the aggregations of bacteria were characterized by an angular zig-zag perimeter. Two main configurations were found. One consisted of a compact collection of bacteria, which we refer to as 'rough compact' (Pl. 1, fig. 7; Pl. 2, figs. 18-23). This colonial form appears to be the rough-phase equivalent of the compact colony of smooth phase cultures. The time-lapse series of a 'rough compact' colony (Pl. 2, figs. 18-23), however, emphasizes the distinctive characteristics which it has. These consist of angle formation between the bacteria, a rate of palisading much slower than smooth phase, and an irregular colony perimeter due to angular outcroppings of organisms. These outcroppings eventually give rise to columns of bacterial chains. The aggrega- 
tion now begins to transform into a quite different aspect which may be described as 'rough nodal' (Pl. 1, fig. 8). This consists of a column of bacteria along which are interposed compact nodes. The rough nodal configuration was also observed to develop directly from chains of bacteria without the initial formation of the rough compact grouping. Both of the rough-phase microcolonial forms were observed with all the methods of cultivation. Eventually, the continued production of organisms rounded out the irregular outline of the rough nodal form so that it resembled the compact configuration.

The primary post-fission movement in rough phase at $37^{\circ}$ and room temperature also was palisading. As a general rule, palisading was through the same process as in smooth-phase microcolonies. The rate at which palisades developed, however, was much slower than in smooth-phase cultures. The difference in palisading rate can be readily seen by comparing smooth- and rough-phase microcolonies at approximately the same bacterial counts. We have done this at the 12- to 15organism stage in $\mathrm{Pl}$. 2, figs. 15, 22 and 25. Both the smooth-phase compact colonies shown (Pl. 2, figs. 15, 25) have all their organisms involved in at least one palisade, while the rough-phase colony ( $\mathrm{Pl} .2$, fig. 22$)$ has only half its organisms palisaded.

Two instances were observed early in cultivation of rough phase bacteria at $37^{\circ}$ in which palisades were created by the folding or buckling of a chain of bacteria (Pl. 3, figs. 37, 38). Both these cases developed in the Fleming closed chamber.

On tracing the family history of the bacteria in a microcolony, from either smoothor rough-phase culture, it was found that in most cases the descendants of organism $1_{1}$ could be separated from the descendants of organism $1_{2}$ by a long axis running through the centre of the microcolony (Pl. 2, fig. 17). In some cases this regularity was disturbed by an aberrant bacterium. Thus, disruption in one microcolony was found to be due to a single bacterium which had deviated medially during the formation of an early palisade (Pl. 2, figs. 24-27), and which had consequently penetrated into the mass of bacteria produced in the other line. Sublines of organisms $1_{1}$ and $1_{2}$ were also usually found to be separated along axes parallel to that separating the $I_{1}$ and $1_{2}$ lines.

The results obtained from the cultivations at $44^{\circ}$ were strikingly different in some respects from those obtained at $37^{\circ}$ and at room temperature, with both smooth and rough phases. There was a greater tendency for filaments to appear, but the most striking difference was the absence of sliding palisades ( $\mathrm{Pl}$. 3, figs. 30 36). In these cases, the configuration was established simply by the bacteria pushing each other about. This led, in some instances, to buckling palisades. The extracellular material which formed broad bridges between bacteria when palisading occurred at $37^{\circ}$ was found confined to narrow strands which did not shift in position as the bacteria were pushed about. Few of these strands were present. When bacterial lines were identified, it was clear that genealogical distributions were as orderly as at $37^{\circ}$ (Pl. 3, fig. 36).

\section{DISCUSSION}

The hypothesis of Dean \& Hinshelwood (1957) that the irregularities of the agar surface play an important role in the order of organisms in microcolonies had led us to a close examination of the entire surface of our preparations. However, the large differences in the ordering of organisms which were consequently detected in the different zones of the open and closed chamber preparations appear to be due largely 
to variations in the thickness of the surface film of fluid, one extreme of which led to the 'broth' zone, detected in the closed chamber preparations only, and the other extreme of which led to early piling up of bacteria in the microcolony. As illustrated in Fig. 2, the broth zone in all probability is in the meniscus formed by the border of the broth film on the agar coming into contact with the glass slide.

Our observation that motile Escherichia coli organisms broke away only from the side of late 'transitional' microcolonies bordering on the intermediate zone also may be explained by film thickness. Apparently the intermediate zone film of fluid tapers off from the maximum thickness of the broth zone to the minimum film thickness of the central zone.

It is possible that the observation of Pearce \& Powell (1951) that motile forms begin to appear in microcolonies of Bacillus subtilis after incubation for 4-5 hr. was made on transitional microcolonial forms. These investigators suggested that motility develops because of an increase in the fluid film in which the organisms lie. Presumably the metabolic products of the bacteria alter the osmotic balance in the surface film sufficiently to extract water from the underlying agar. This hypothesis does not appear to be pertinent to our system in view of the characteristic location of motile organisms in the transitional microcolonies only on the side toward the periphery of the preparation.

The intercellular bridging in the bacterial aggregations of the peripheral and central zones is open to at least two interpretations. Some of the bridges suggest an exchange of material between the organisms. This appearance strongly resembles published photographs of presumptive bacterial conjugation (Lederberg, 1956). From our own observations, however, the 'conjugation' configurations of Lederberg may be nothing more than the early stages of palisading (compare fig. 1 of Lederberg, 1956, with Pl. 2, fig. 19). It appears more probable to us that the bridging observed in the present study was simply due to adhesion through capsular material. The difference in optical density between peripheral and interior bacteria of the microcolony with dark-phase optics may be an artefact.

It is apparent that characteristic microcolony formations of the central zone appeared quite early, and could be recognized in most cases almost as soon as the minimal number of bacteria required for a formation had appeared. The early microcolonies presented a graded series of forms, which were repeatedly demonstrated in preparation after preparation. Our observations of both smooth and rough phases of Escherichia coli are essentially in agreement with those of Nutt (1927) made by direct microscopic study of Salmonella aertrycke, $S$. paratyphosa $B$ and $S$. enteritidis, and with those of Seal (1937) who studied cholera vibrios by the same direct method as did Nutt.

On the basis of morphology alone, no cellular difference was discernible between smooth- and rough-phase organisms of Escherichia coli, a point which $\mathrm{Hu}$ (1936) had earlier emphasized in microculture studies of Salmonella typhimurium. We did not observe any tendency in rough phase for the growth of the extremely long filaments of the medusa-head colony, which Bisset (1938) considered to be the typical expression of the rough phase in Escherichia coli. Our rough-phase microcultures, rather, resembled closely those described by Nutt (1927) and Seal (1937). Schneweis (1959), similarly, found that only 2 of 7 strains of rough-phase Enterobacteriaceae gave medusa-head colonies in microculture. 
Palisading, the primary movement by which our bacteria aggregated, cannot be considered a cultural artefact resulting from mechanical restraint, as suggested by Bisset (1950), since we found it in both the closed and open chamber techniques at $37^{\circ}$ and room temperature. Graham-Smith (1910) investigated this possibility 50 years ago by following the development of colonies on the surface of agar in Petri plates; he concluded that mechanical restraint did not account for palisading. Among the new evidence obtained in the present study bearing on this problem is the observation, with the Fleming closed chamber method, of a vertical displacement of a proximal cell end, and the subsequent appearance of the palisade, with the bacteria continuing to lie in two planes. It would seem that if any pressure from the agar were present it would have forced the bacteria back into the same horizontal plane. Clonal microcolony formation without palisading, in agreement with Bisset's point of view, was observed only in cultivations at $44^{\circ}$. It is possible that the capsular material, through which the palisading movement appears to occur, undergoes a transformation from a sol to gel at the elevated temperature.

The regular distribution by bacterial lines of the bacteria within the clonal microcolony demonstrates the high degree of order present. Previous failures to appreciate this (Bisset, 1938; Schneweis, 1959) undoubtedly were due to a failure to follow the genealogical history of the microcolony.

The dynamics of microcolony formation at $37^{\circ}$ appear to depend primarily upon the fact that growth is in the direction of the longitudinal axis of the bacterium. The naturally undisturbed order, therefore, would be that of a chain of bacteria. As the microcolony begins to exhibit palisading, the concept of available free space, developed on the basis of fibroblast tissue culture studies (Abercrombie \& Heaysman, 1954), becomes illuminating. The bacterial microcolony, once palisading is initiated, may be regarded as a spatial distortion of a single chain of bacteria. When the palisading movements have established 3 or more columns of bacteria, the exterior organisms will continue to form new palisades, but the interior columns will develop unbroken because of constraint by the adjoining organisms. The interior columns, therefore, have reverted to the initial form of aggregation, with the new possibility of growing into considerably longer chains. From preliminary studies of overnight cultivations (not described in the present report), it is apparent that extension is not unlimited. Centrally located interior bacteria are forced up above the plane of the original monolayer, and a second smaller layer of bacteria develops. As the process continues, the typical convexity of a large colony gradually evolves. The interplay of movements and constraints regularly leads to a circular colony form regardless of the early microcultural configuration. At $44^{\circ}$ with the loss of palisading as a factor in the aggregation of the bacteria, close packing does not occur, but the formations nevertheless eventually become circular also. The bacterial microcolonial forms we have described resemble, in some respects, the monolayer aggregations of fibroblasts in tissue culture. Abercrombie \& Heaysman (1954) found that the adhesion of fibroblasts to each other results in a characteristic meshwork which has a striking resemblance to the open aspect of our Escherichia coli microcolonies at $44^{\circ}$. The direction of movement of fibroblasts, once they have contacted each other and are adhering, is controlled by the position of the free space. Consequently, whatever the original shape of the culture, it will tend to assume a circular form as it continues to grow. A considerable number of problems 
remain to be clarified before the mechanisms of bacterial colony formation will be understood. With elucidation of this phenomenon, it may well be that new light may be thrown upon the more complicated processes of cell aggregation in higher phyla.

The authors are greatly indebted to Dr Emil Borysko and Mr William A. Stylos for their aid in the early phases of this study. Support was received through research grants from the National Institutes of Health, Bethesda, Maryland, U.S.A.

\section{REFERENCES}

Abercrombie, M. \& Heaysman, J. E. M. (1954). Observations on the social behaviour of cells in tissue culture. II. 'Monolayering' of fibroblasts. Exp. Cell Res. 6, 293.

Bayne-Jones, S. \& Adolph, E. F. (1932). Growth in size of microorganisms measured from motion pictures. III. Bacterium coli. J. cell. comp. Physiol 2, 329.

Bisset, K. A. (1938). The structure of 'rough' and 'smooth' colonies. J. Path. Bact. 47, 223.

Bisset, K. A. (1950). The Cytology and Life-History of Bacteria, p. 65. Baltimore: Williams and Wilkins.

Dean, A. C. R. \& Hinshelwood, C. (1957). The formation of papillae on bacterial colonies. II. Proc. Roy. Soc. B, 147, 10.

Fleming, A., Voureka, A., Kramer, I. R. H. \& Hughes, W. H. (1950). The morphology and motility of Proteus vulgaris and other organisms cultured in the presence of penicillin. J. gen. Microbiol. 4, 257.

Graham-Smite, G. (1910). The division and post-fission movements of bacilli when grown on solid media. Parasitology, 3, 17.

Hu, K. (1936). Studien über den Entwicklungsmodus der Bakterien bei Einzellkultur auf Nährbodenfilm. III. Mitteilung. Beobachtungen über den Entwicklungsmodus der S- und R-Form der Bakterien. Jap. J. exp. Med. 14, 67.

Hughes, W. H. (1953). The origin of the L-form variants in anaerobic cultures of Bacterium coli. J. gen. Microbiol. 8, 307.

KNAYSI, G. (1951). Elements of Bacterial Cytology, 2nd ed., p. 290. Ithaca, N.Y.: Comstock Publishing Co.

LeDERBERg, J. (1956). Conjugal pairing in Escherichia coli. J. Bact. 71, 497.

Minck, R., EbeL, J.-P. \& Minck, A. (1950). Le choix du fixateur en cytologie bactérienne. C.R. Soc. Biol., Paris, 144, 288.

NuTT, M. M. (1927). The method of division of the rough and smooth type of colonies among the bacilli of the Salmonella group. J. Hyg., Camb. 26, 44.

Pearce, T. W. \& Powell, E. O. (1951). New techniques for the study of growing organisms. J. gen. Microbiol. 5, 91.

Pulventaft, R. J. V. (1952). Effects of antibiotics on growing cultures of Bacterium coli. J. Path. Bact. 64, 75.

SchNeweIs, K.-E. (1959). Zur Mikromorphologie glatter und rauher EnterobacteriaceenKulturen. Zbl. Bakt. (1 Abt. Orig.), 176, 71.

SEAL, S. C. (1937). Rough and smooth cholera vibrios in relation to their mode of division and growth. Indian J. med. Res. 24, 991.

Topley and Wilson's Principles of Bacteriology and Immunity (1955). 4th ed. Ed. G. S. Wilson \& A. A. Miles, p. 41. Baltimore: Williams and Wilkins. 


\section{EXPLANATION OF PLATES}

Plate 1

Figs. 1-4. Cellular aggregates in peripheral zone of the microculture. Dark-phase contrast, $\times 1250$.

Fig. 1. Motile chain of rough-phase microculture (arrow indicates motile organism).

Fig. 2. Angular folding in bacterial chain; rough-phase microculture.

Fig. 3. Aggregation of rough-phase organisms after $5 \mathrm{hr}$. incubation.

Fig. 4. Aggregation of smooth-phase organisms following overnight incubation.

Fig. 5. Transitional microcolony in smooth-phase culture, overnight incubation; closed chamber method of cultivation. Dark-phase contrast, $\times 1250$.

Fig. 6. Rough-phase organism chains in the intermediate zone; overnight incubation. Darkphase contrast, $\times 1250$.

Figs. 7-10. Cellular aggregations in central zone. Dark phase contrast, $\times 1250$.

Fig. 7. Compact rough clonal microcolony after $4 \mathrm{hr}$.; Fleming method of incubation.

Fig. 8. Nodal rough clonal microcolony following overnight incubation; open chamber method of cultivation.

Fig. 9. Coccobacilli in smooth-phase microcolony; overnight incubation; open chamber method of cultivation.

Fig. 10. Peripheral filament in rough-phase microcolony following overnight incubation; closed chamber preparation.

\section{Plate 2}

Figs. 11-17. Time-lapse series of compact smooth-phase clonal microcolony; times are given at top of each figure, with 0 time taken at first division. Bright field optics; open chamber preparation; $\times \mathbf{1 8 0 0}$.

Figs. 11-14. Genealogical identification of the bacteria in the clone.

Fig. 17. Spatial distribution of bacterial lines $1_{1}$ and $\mathbf{1}_{2}$ in a well developed clonal microcolony.

Figs. 18-23. Time-lapse series of a compact rough clonal microcolony; Fleming method of cultivation. Dark-phase contrast optics; $\times 1800$.

Figs. 24-27. Time-lapse series of longitudinal compact clone, with disrupted spatial distribution of cell lines, $1_{1}$ and $I_{2}$; open chamber method. Bright field optics; $\times 2000$.

Fig. 28. Intercellular bridging of coccobacilli in the peripheral zone of the culture. Dark-phase contrast, $\times 4800$.

Fig. 29. Intercellular bridging of rough-phase organisms in a clonal microcolony of the central zone. Dark-phase contrast; $\times \mathbf{4 8 0 0}$.

\section{Plate 3}

Figs. 30-36. Time-lapse series of smooth-phase microcolony (young inoculum) at $44^{\circ}$. Dark-phase contrast optics, Fleming technique $; \times 1250$.

Figs. 30-35. Early stages in the development of the microcolony; note the parallelism attained simply through pushing about of bacteria. Capsular adhesions are almost entirely absent ( $a$ indicates an abortive sliding palisade; $b$ illustrates parallelism of organisms through a buckling movement).

Fig. 36. Configuration of the well developed clone, with genealogical distribution of bacterial lines $1_{1}$ and $1_{2}$. Note the open appearance of the colony.

Figs. 37, 38. Initial movements in the formation of a buckling palisade at $37^{\circ}$ in the rough phase ; Fleming method of cultivation. Dark-phase contrast optics; $\times 1800$. 


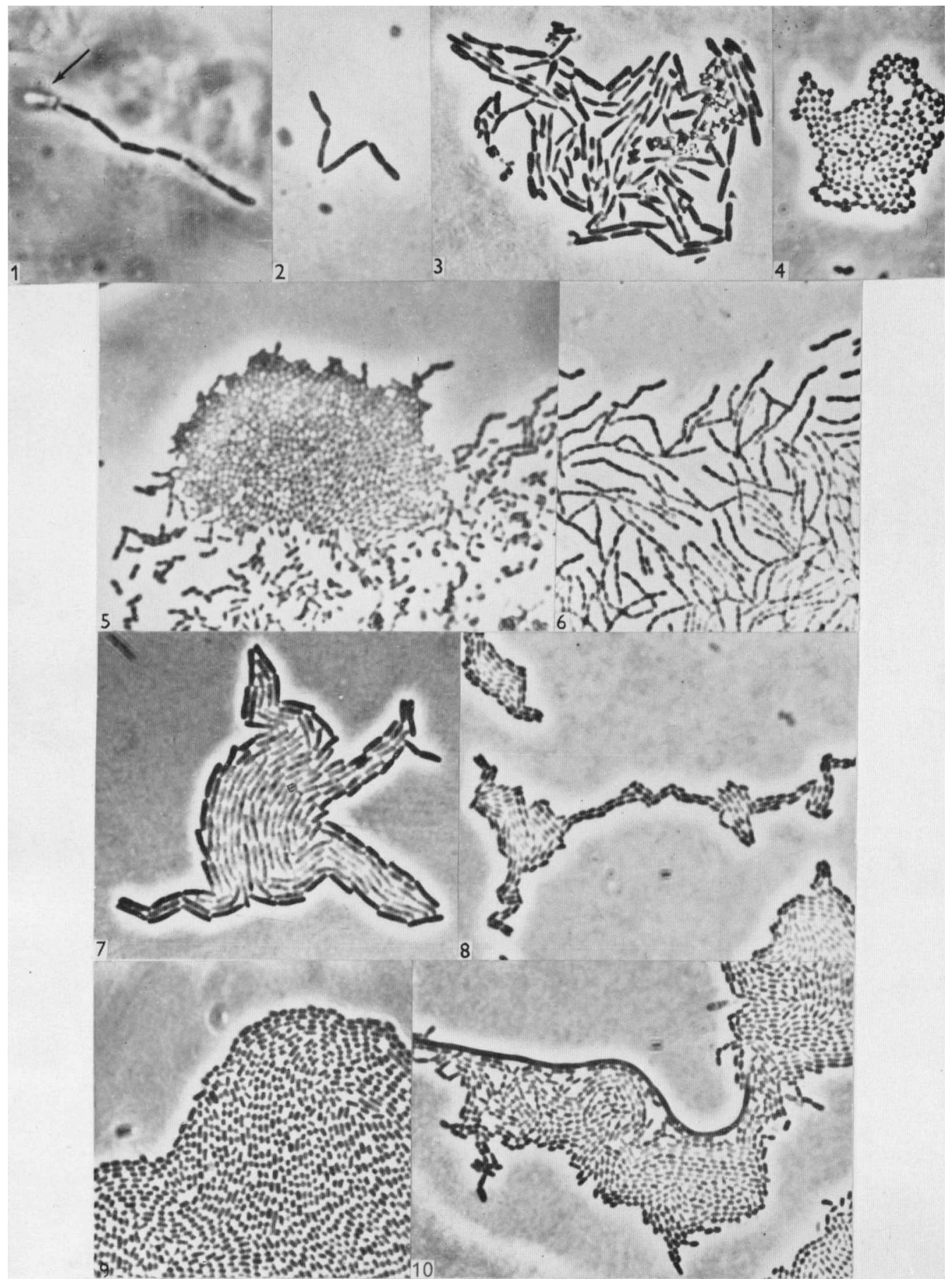


Journal of General Microbiology, Vol. 25, No. 3

Plate 2

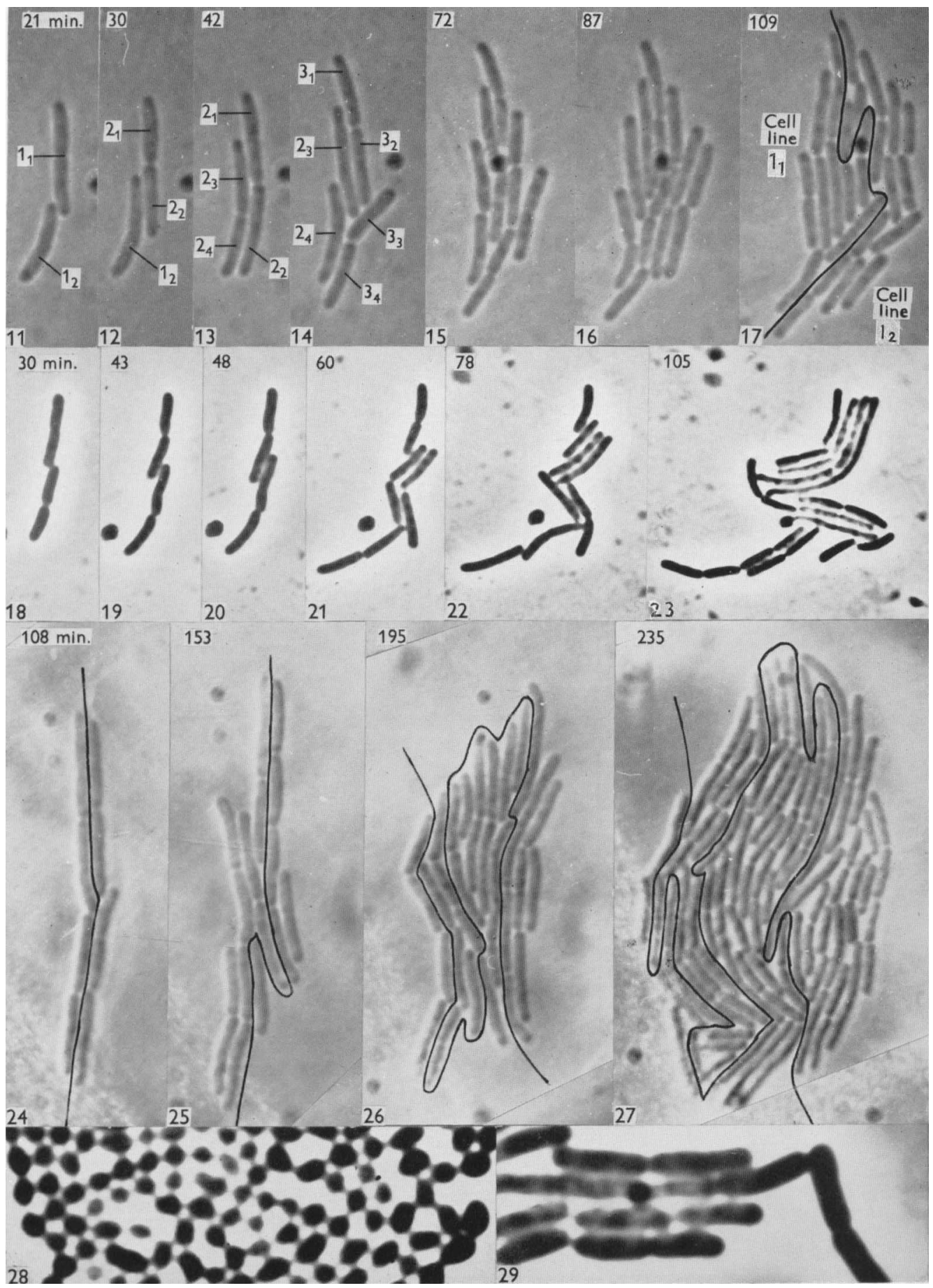

H. HOFFMAN AND M. E. FRANK 
Journal of General Microbiology, Vol. 25, No. 3

Plate 3

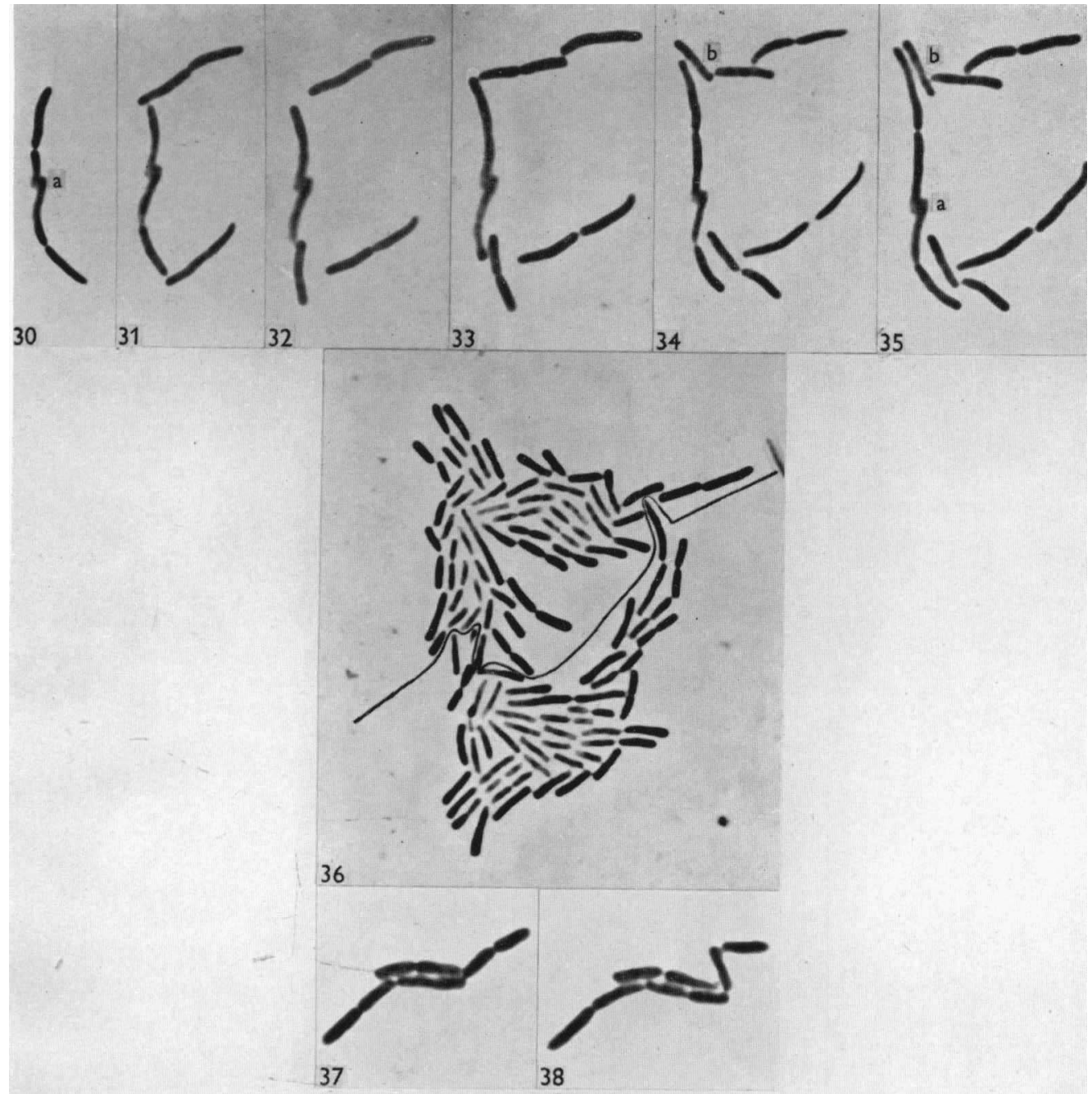

H. HOFFMAN AND M. E. FRANK 